\title{
Phase Evolution in Lead-free Cs-doped FASnI 3 Hybrid Perovskites and Optical Properties
}

Pimsuda Pansa-Ngat, ${ }^{a}$ Hideki Nakajima, ${ }^{\mathrm{b}}$ Ratchadaporn Supruangnet, ${ }^{\mathrm{b}}$ Sujin Suwanna, ${ }^{\mathrm{c}}$ Pasit

Pakawatpanurut, ${ }^{\mathrm{d}, \mathrm{f}}$ Somboon Sahasithiwat, ${ }^{\mathrm{e}}$ and Pongsakorn Kanjanaboos a,f, *

a School of Materials Science and Innovation, Faculty of Science, Mahidol University, Nakhon Pathom 73170, Thailand

${ }^{\mathrm{b}}$ Synchrotron Light Research Institute, Nakhon Ratchasima, 30000, Thailand

${ }^{c}$ Department of Physics, Faculty of Science, Mahidol University, Bangkok 10400, Thailand

${ }^{\mathrm{d}}$ Department of Chemistry, Faculty of Science, Mahidol University, Bangkok 10400, Thailand

${ }^{\mathrm{e}}$ National Metal and Materials Technology Center (MTEC), Pathum Thani 12120, Thailand

${ }^{\mathrm{f}}$ Center of Excellence for Innovation in Chemistry (PERCH-CIC), Ministry of Higher Education, Science, Research and Innovation, Bangkok 10400, Thailand

*pongsakorn.kan@mahidol.edu

\section{Supporting Information}




\section{Perovskite solution}

$\mathrm{Cs}_{\mathrm{x}} \mathrm{FA}_{1-\mathrm{x}} \mathrm{SnI}_{3}$ perovskite solutions were prepared by mixing $0.8 \mathrm{M} \mathrm{FASnI} 3$ and $0.8 \mathrm{M} \mathrm{CsSnI} 3$ at appropriate volume ratios. The ratios of CsI, abbreviated as $x$, were varied from 1, 3, 5, 10, 30, 50, 70, 90 and 100\% v/v. To prepare 0.8M FASnI 3 , 0.88M SnI 2 (99\% purity, Alfa Aesar) was predissolved in 15:1 v/v anhydrous DMF:DMSO at $70{ }^{\circ} \mathrm{C}$. $0.1 \mathrm{M} \mathrm{SnF} 2$ (99\% purity, Sigma-Aldrich) was added as an additive. Then, 0.88 $\mathrm{M} \mathrm{SnI}_{2}$ solution was mixed into 0.8M FAI powder (Dyesol) and kept stirring at $70{ }^{\circ} \mathrm{C}$ for $2 \mathrm{~h}$. Due to solubility limit of CsI crystalline powder in DMF, 0.8M CsI (99\% purity, Sigma-Aldrich) was pre-dissolved in 4:1 v/v DMF:DMSO using vortex. The $0.88 \mathrm{M} \mathrm{SnI} 2$ solution, without additive, was mixed with $0.8 \mathrm{M}$ CsI solution and stirred at $70{ }^{0} \mathrm{C}$ for $2 \mathrm{~h}$ to obtain $0.8 \mathrm{M} \mathrm{CsSnI}_{3}$. The series of $0.8 \mathrm{M} \mathrm{Cs}_{\mathrm{x}} \mathrm{FA}_{1-\mathrm{x}} \mathrm{SnI}_{3}$ solutions were continuously stirred at $70{ }^{0} \mathrm{C}$ overnight. The final solutions were filtered before use.

\section{Film fabrication process}

Films were casted by one-step spin-coating technique on $\mathrm{FTO} / c-\mathrm{TiO}_{2} / m-\mathrm{TiO}_{2}$ substrates, where $c$ $\mathrm{TiO}_{2}$ is compact- $\mathrm{TiO}_{2}$ layer ${ }^{1}$ and $m-\mathrm{TiO}_{2}$ is mesoporous- $\mathrm{TiO}_{2}$ layer ${ }^{2}$. After cleaning by $\mathrm{UV}$ ozone for 30 mins, the substrates were transferred into $\mathrm{N}_{2}$-filled glovebox and pre-heated at $70{ }^{0} \mathrm{C}$. To fabricate the film, $50 \mu \mathrm{l}$ of perovskite solution was dropped at $5^{\text {th }} \mathrm{s}$ on the spinning substrate, then $400 \mu 1$ of chlorobenzene, CB $\left(99.8 \% \mathrm{v} / \mathrm{v}\right.$, Sigma-Aldrich) was dripped at $18^{\text {th }} \mathrm{s}$ after spinning. The spin condition was $1000 \mathrm{rpm}$ for $30 \mathrm{~s}$. with initial acceleration of $4000 \mathrm{rpm} / \mathrm{s}$. Finally, the casted film was annealed at $100{ }^{\circ} \mathrm{C}$ for 15 minutes.

\section{PMMA coating}

To prevent the films from exposing to oxygen and humidity, thin layer of PMMA was coated on top of the perovskite films before performing the characterizations except for X-ray diffraction (XRD), ultraviolet photoelectron spectroscopy (UPS) and X-ray photoelectron spectroscopy (XPS). After the casted film was cooled down, $80 \mu 1$ of $50 \mathrm{mg} / \mathrm{ml}$ of PMMA in CB was gradually dropped on the entire film and then spun at $1500 \mathrm{rpm}$ for $45 \mathrm{~s}^{3}$ 
(a)

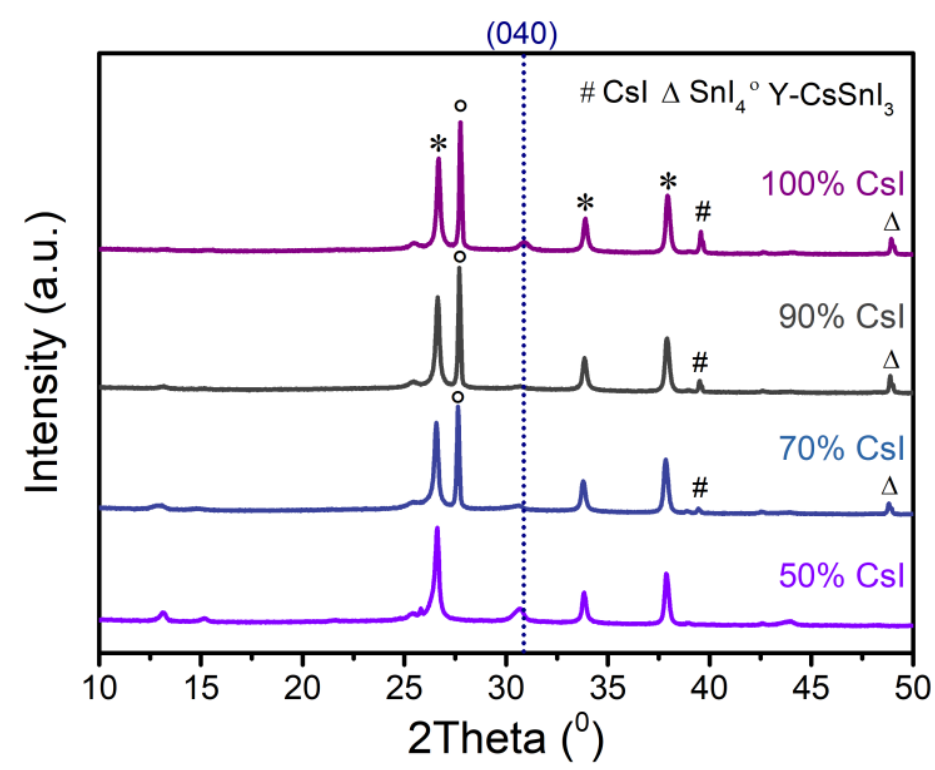

(b)
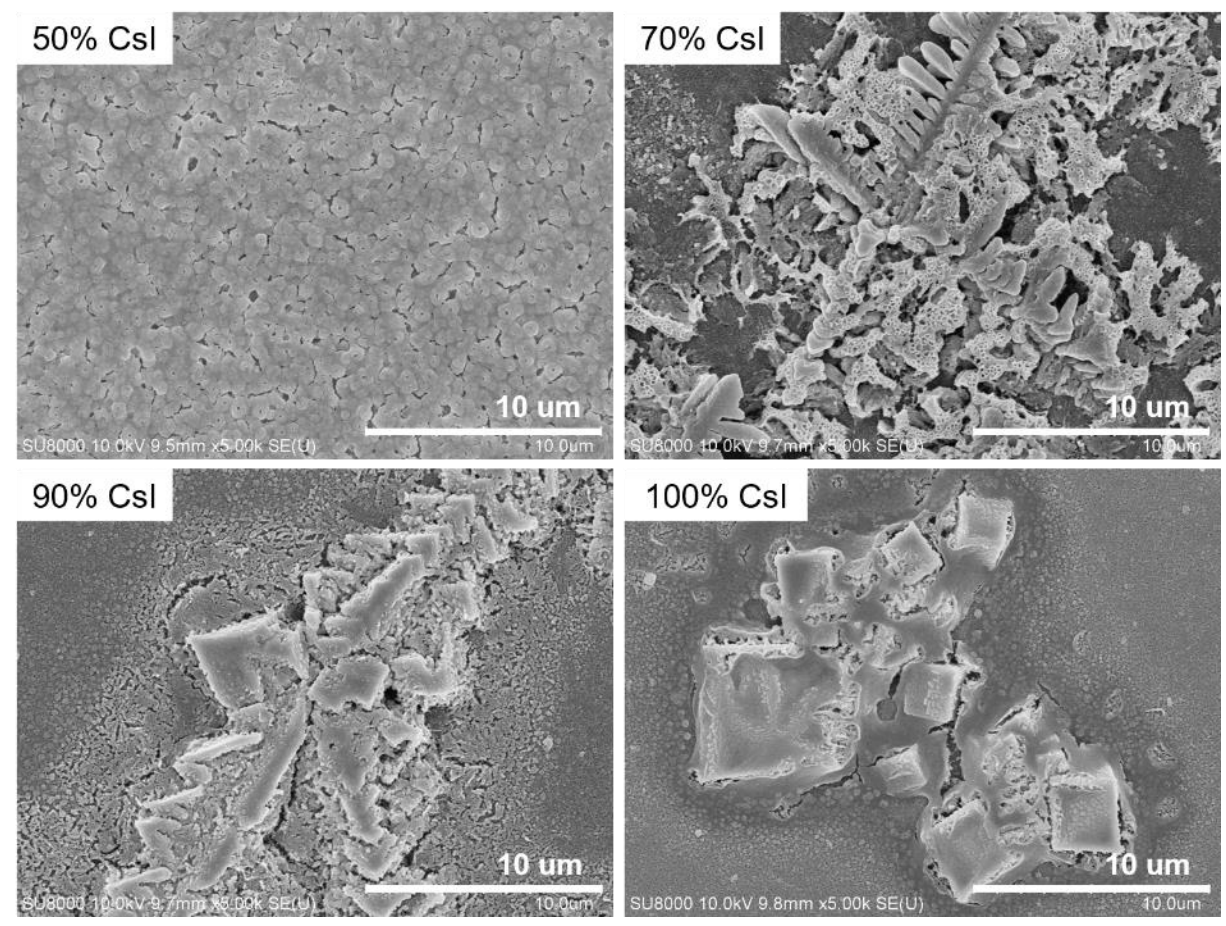

Figure S1. (a) XRD spectra of 50\% (violet), 70\% (blue), 90\% (gray) and 100\% (purple) CsI films. The peaks correspond to substrate are labelled by (*). (b) SEM surface morphologies of 50\%, 70\%, $90 \%$ and $100 \%$ CsI films. 
(a)

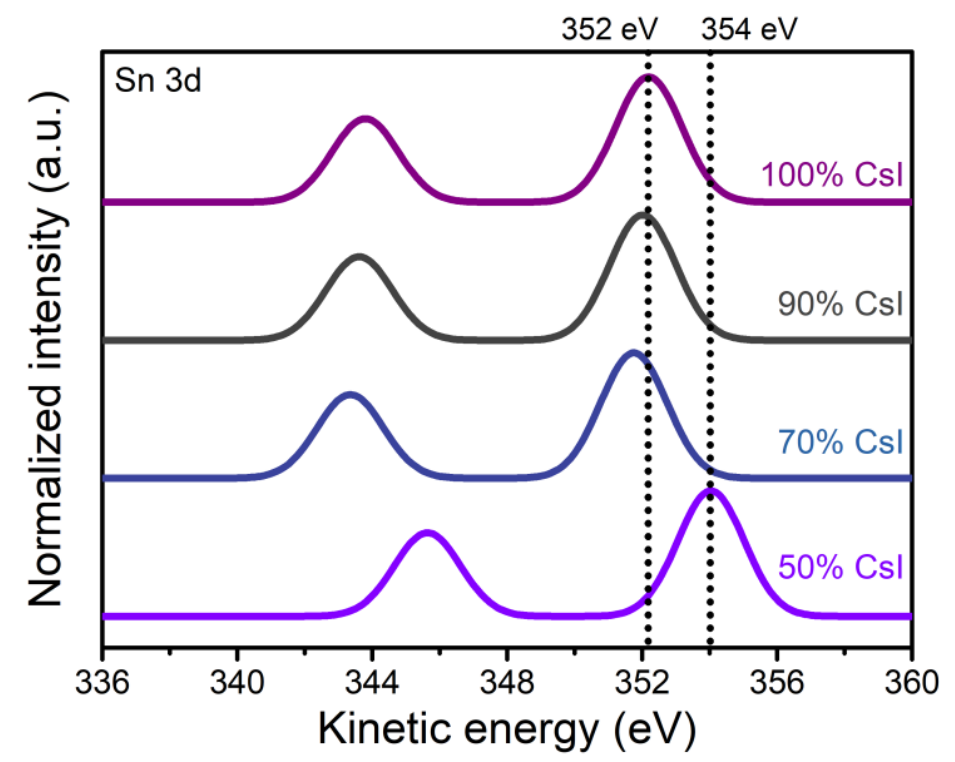

(b)

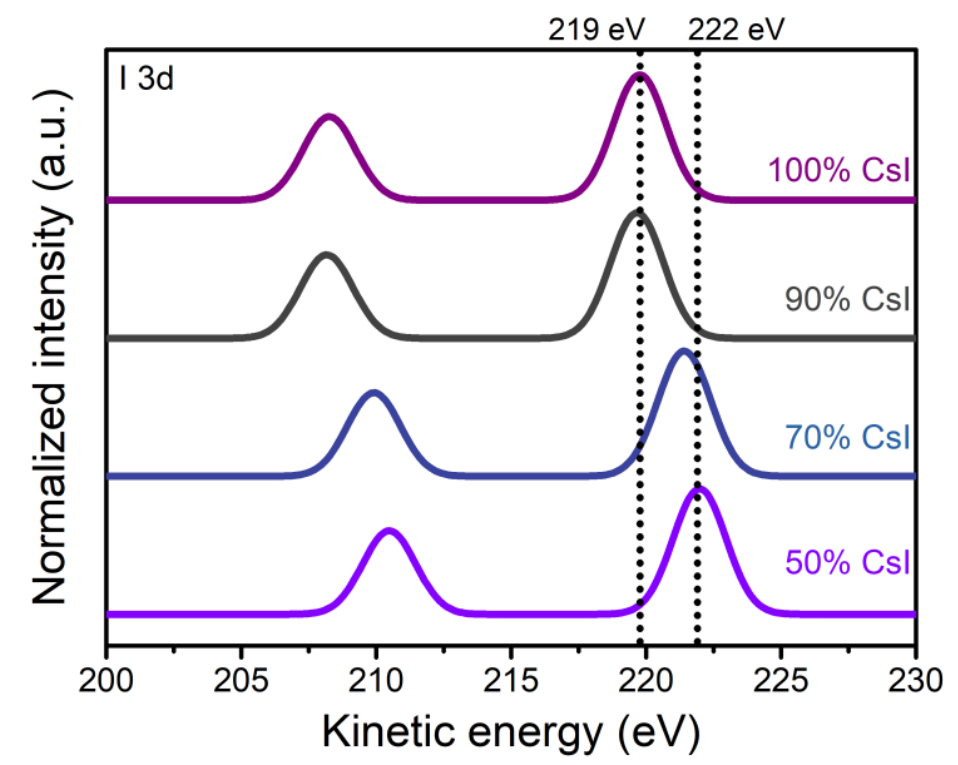

Figure S2. XPS spectra of 50\% (violet), 70\% (blue), 90\% (gray) and 100\% (purple) CsI films for (a) Sn $3 d$ and (b) I 3d. Short dot lines are represented $\mathrm{Sn} 3 \mathrm{~d}_{5 / 2}$ and I $3 \mathrm{~d}_{5 / 2}$ peak positions, respectively. 
(a)

$$
30 \% \mathrm{Csl}-\mathrm{Cs} 3 \mathrm{~d}
$$

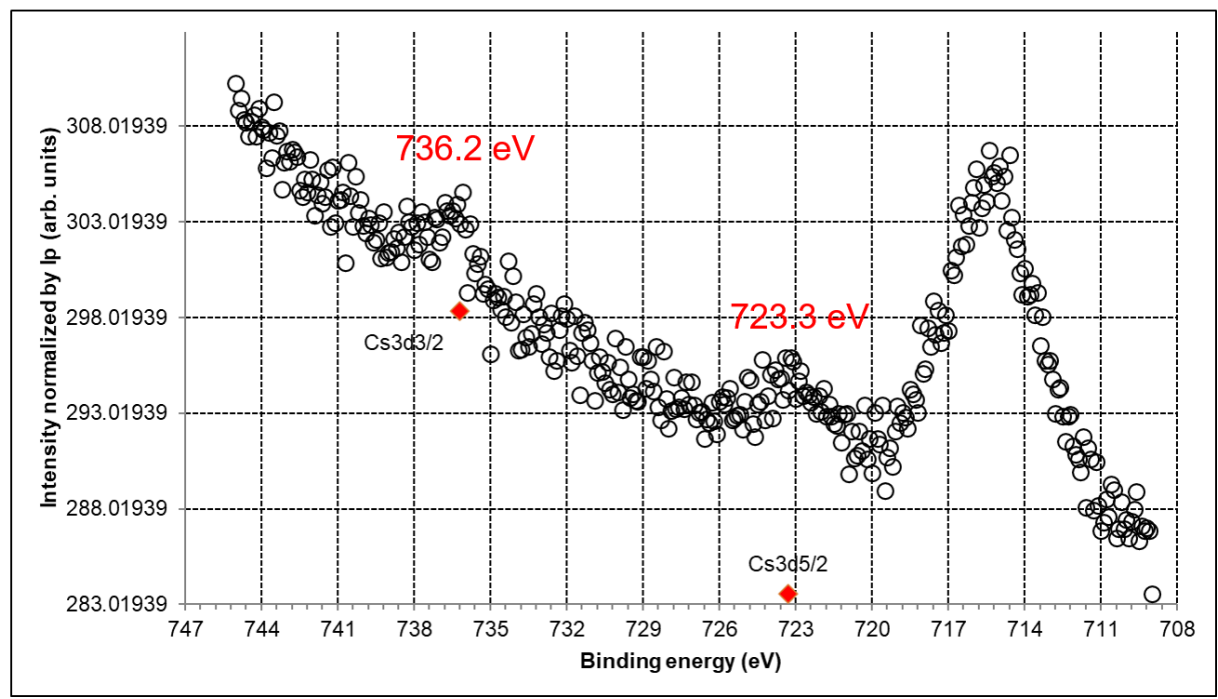

(b)

$$
50 \% \mathrm{Csl}-\mathrm{Cs} 3 \mathrm{~d}
$$

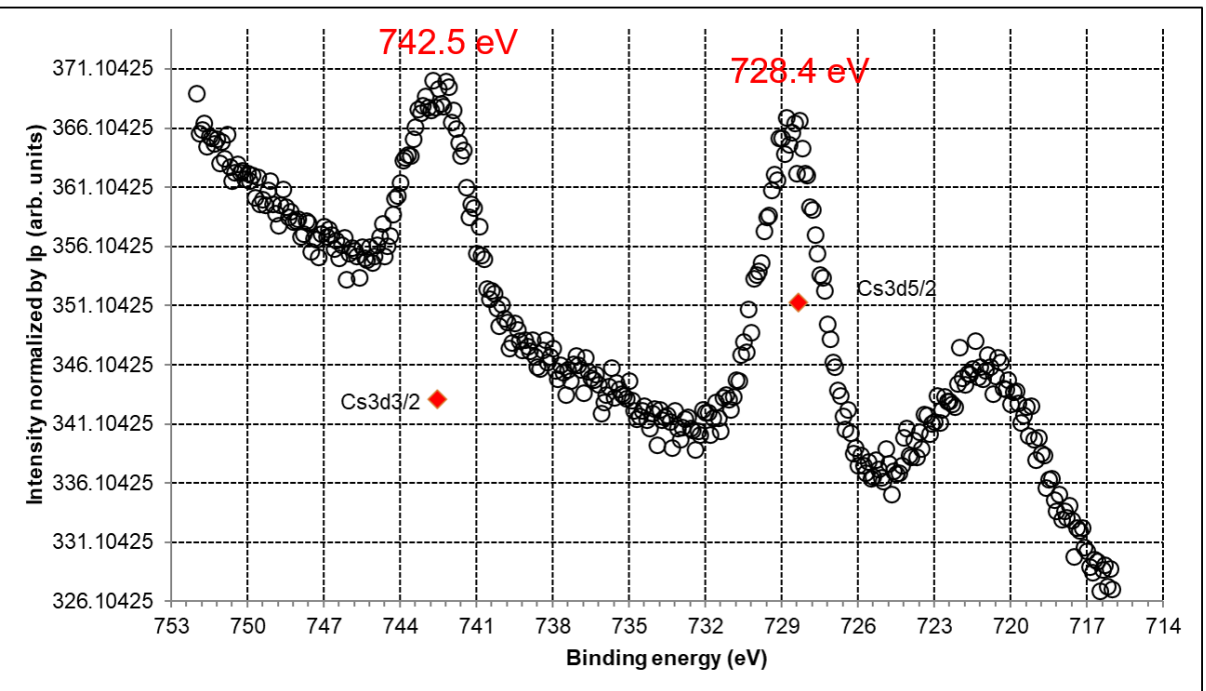

Figure S3. XPS spectra of Cs $3 \mathrm{~d}_{3 / 2}$ and Cs $3 \mathrm{~d}_{5 / 2}$ peaks of (a) $30 \%$ CsI and (b) $50 \%$ CsI films. 
(c)

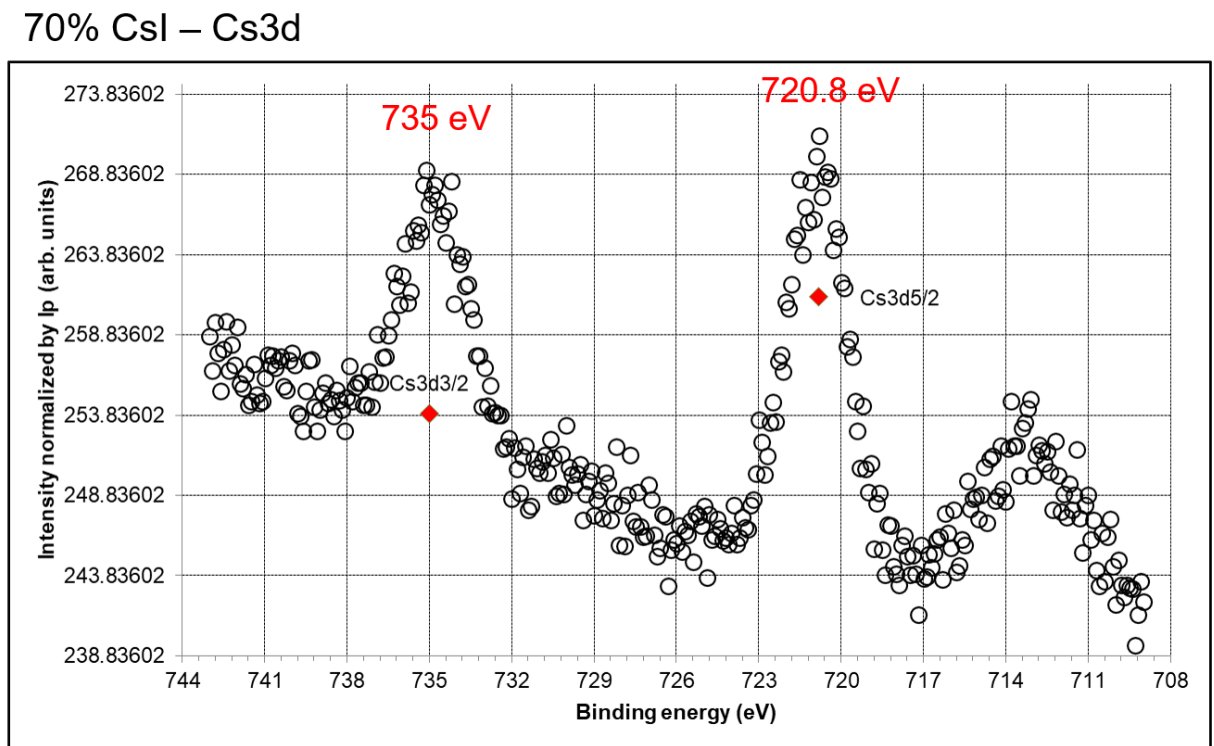

(d)

$$
90 \% \mathrm{CsI}-\mathrm{Cs} 3 \mathrm{~d}
$$

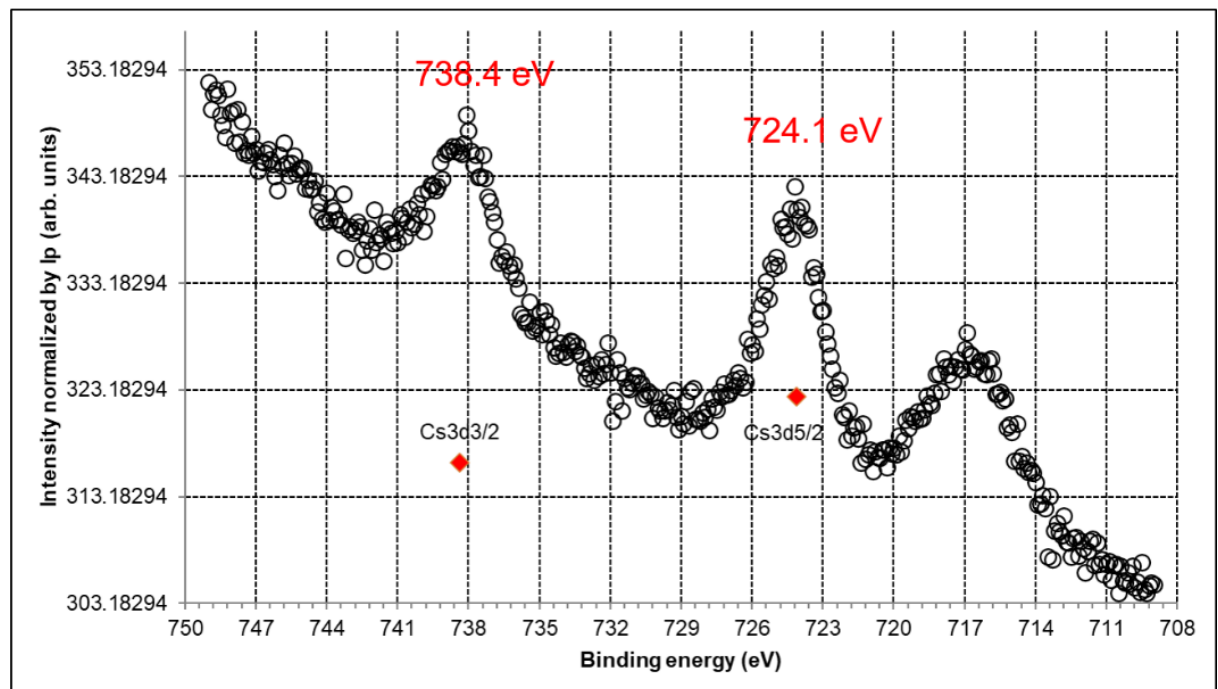

Figure S3. XPS spectra of Cs $3 d_{3 / 2}$ and Cs $3 d_{5 / 2}$ peaks of (c) $70 \%$ CsI and (d) $90 \%$ CsI films. 
(e)

$100 \% \mathrm{CsI}-\mathrm{Cs} 3 \mathrm{~d}$

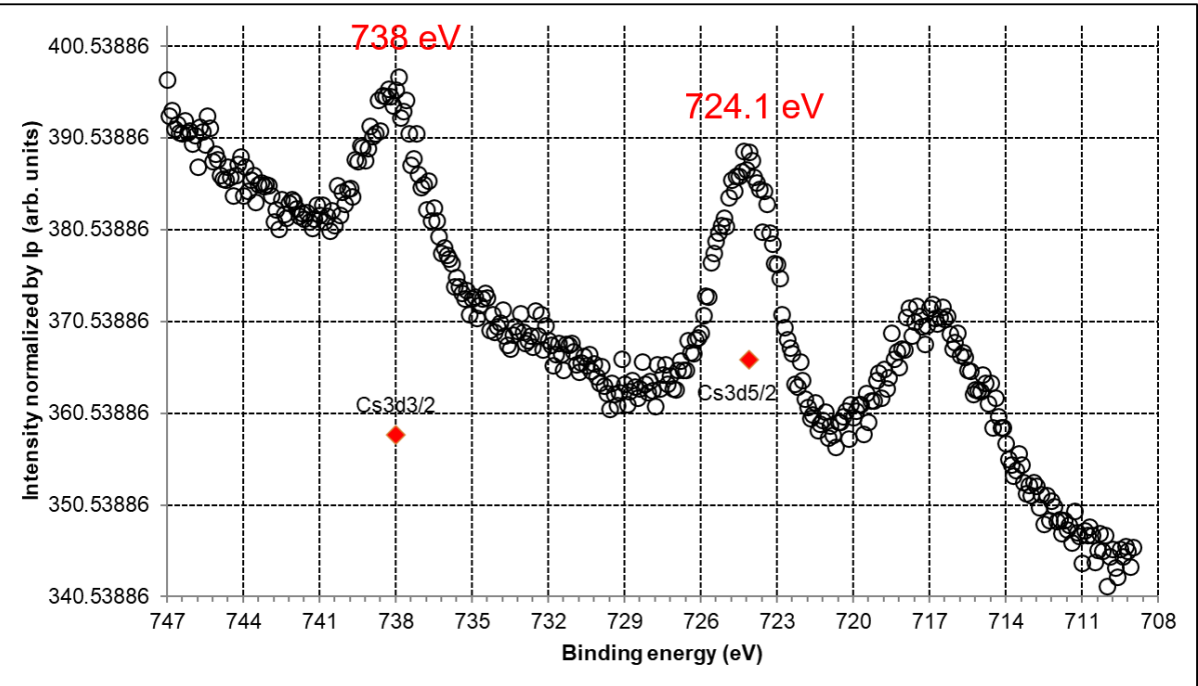

Figure S3. XPS spectra of Cs $3 d_{3 / 2}$ and Cs $3 d_{5 / 2}$ peaks of (e) $100 \%$ CsI films. 


\section{Atomic concentration calculation}

We calculated the atomic concentration from XPS spectra using the following formulae. ${ }^{4}$

$$
C_{x}=\frac{I_{x} / S_{x}}{\sum_{i} I_{i} / S_{i}}
$$

Where $C_{x}$ is fraction of element $x, I_{x}$ is peak area of element $x, S_{x}$ is relative sensitivity of photoelectron peak $x$ and $\sum$ is sum over all elements.

Table S1. The atomic concentration of Sn $3 \mathrm{~d}$ and I $3 \mathrm{~d}$ and ratios of $\mathrm{Sn} 3 \mathrm{~d} / \mathrm{I} 3 \mathrm{~d}, \mathrm{Sn}^{2+}-\mathrm{I}(\%), \mathrm{Sn}^{4+}-\mathrm{I}(\%), \mathrm{Sn}^{4+}-\mathrm{O}_{(\%)}$ and $\mathrm{Sn}^{2+} / \mathrm{Sn}^{4+}$ at various Cs contents (0 - 100\% CsI).

\begin{tabular}{|c|c|c|c|c|c|c|c|}
\hline Cs contents & Sn 3d (\%) & I 3d (\%) & Sn 3d/I 3d & $\mathrm{Sn}^{2+}$ - I (\%) & $\mathrm{Sn}^{4+}-\mathbf{I}(\%)$ & $\mathrm{Sn}^{4+}-\mathrm{O}(\%)$ & $\mathbf{S n}^{2+} / \mathbf{S n}^{4+}$ \\
\hline 0\% CsI & $46.9 \pm 0.5$ & $53.1 \pm 0.4$ & $0.88 \pm 0.01$ & $78.1 \pm 0.7$ & $21.1 \pm 0.6$ & $0.8 \pm 0.2$ & $3.57 \pm 0.16$ \\
\hline $1 \% \mathrm{CsI}$ & $53.0 \pm 1.6$ & $47.0 \pm 0.8$ & $1.13 \pm 0.05$ & $76.8 \pm 2.2$ & $21.0 \pm 1.2$ & $2.1 \pm 1.3$ & $3.32 \pm 0.45$ \\
\hline 3\% CsI & $50.3 \pm 1.4$ & $49.7 \pm 0.8$ & $1.01 \pm 0.04$ & $73.6 \pm 2.1$ & $20.8 \pm 1.0$ & $5.6 \pm 1.4$ & $2.79 \pm 0.34$ \\
\hline $5 \%$ CsI & $54.5 \pm 1.8$ & $45.5 \pm 0.4$ & $1.20 \pm 0.05$ & $34.4 \pm 2.4$ & $58.5 \pm 1.6$ & $7.1 \pm 1.4$ & $0.52 \pm 0.06$ \\
\hline $10 \% \mathrm{CsI}$ & $48.1 \pm 0.9$ & $51.9 \pm 0.4$ & $0.93 \pm 0.02$ & $56.9 \pm 1.2$ & $15.2 \pm 0.5$ & $27.9 \pm 1.2$ & $1.32 \pm 0.08$ \\
\hline $30 \% \mathrm{CsI}$ & $46.9 \pm 0.4$ & $53.1 \pm 0.4$ & $0.88 \pm 0.01$ & $49.0 \pm 0.6$ & $14.1 \pm 0.4$ & $36.9 \pm 0.5$ & $0.96 \pm 0.03$ \\
\hline $50 \% \mathrm{CsI}$ & $42.4 \pm 0.7$ & $57.6 \pm 0.4$ & $0.74 \pm 0.02$ & $20.9 \pm 1.2$ & $26.1 \pm 0.5$ & $53.0 \pm 1.0$ & $0.26 \pm 0.02$ \\
\hline $70 \%$ CsI & $46.6 \pm 0.8$ & $53.4 \pm 0.4$ & $0.87 \pm 0.02$ & $52.5 \pm 1.2$ & $18.6 \pm 0.7$ & $28.9 \pm 0.8$ & $1.10 \pm 0.06$ \\
\hline $90 \% \mathrm{CsI}$ & $51.3 \pm 2.2$ & $48.7 \pm 0.7$ & $1.05 \pm 0.06$ & $30.6 \pm 2.9$ & $48.8 \pm 1.9$ & $20.7 \pm 2.3$ & $0.44 \pm 0.07$ \\
\hline $100 \% \mathrm{CsI}$ & $53.0 \pm 1.3$ & $47.0 \pm 0.4$ & $1.13 \pm 0.04$ & $41.8 \pm 1.7$ & $35.6 \pm 1.0$ & $22.7 \pm 1.3$ & $0.72 \pm 0.06$ \\
\hline
\end{tabular}




\section{Monte Carlo simulation}

We performed the Monte Carlo simulation on Microsoft Excel macro code [https://doi.org/10.5281/zenodo.1320738 $]^{5}$ to evaluate the standard deviation of peak area and percentage obtained by the least-square curve fitting. After we fitted the model on each spectrum, we extracted the residuals of spectrum from a model in each data point. These residuals are supposed to represent the random noises in the data. Therefore, we randomly resampled these residuals (percentage) to the model to create the simulated data sets, which is the bootstrap method. The simulated data were fitted again with the same model used in the original data. We used 10 data sets to evaluate the standard deviation in each spectrum, resulting in a similar standard deviation obtained from 100 data sets. 

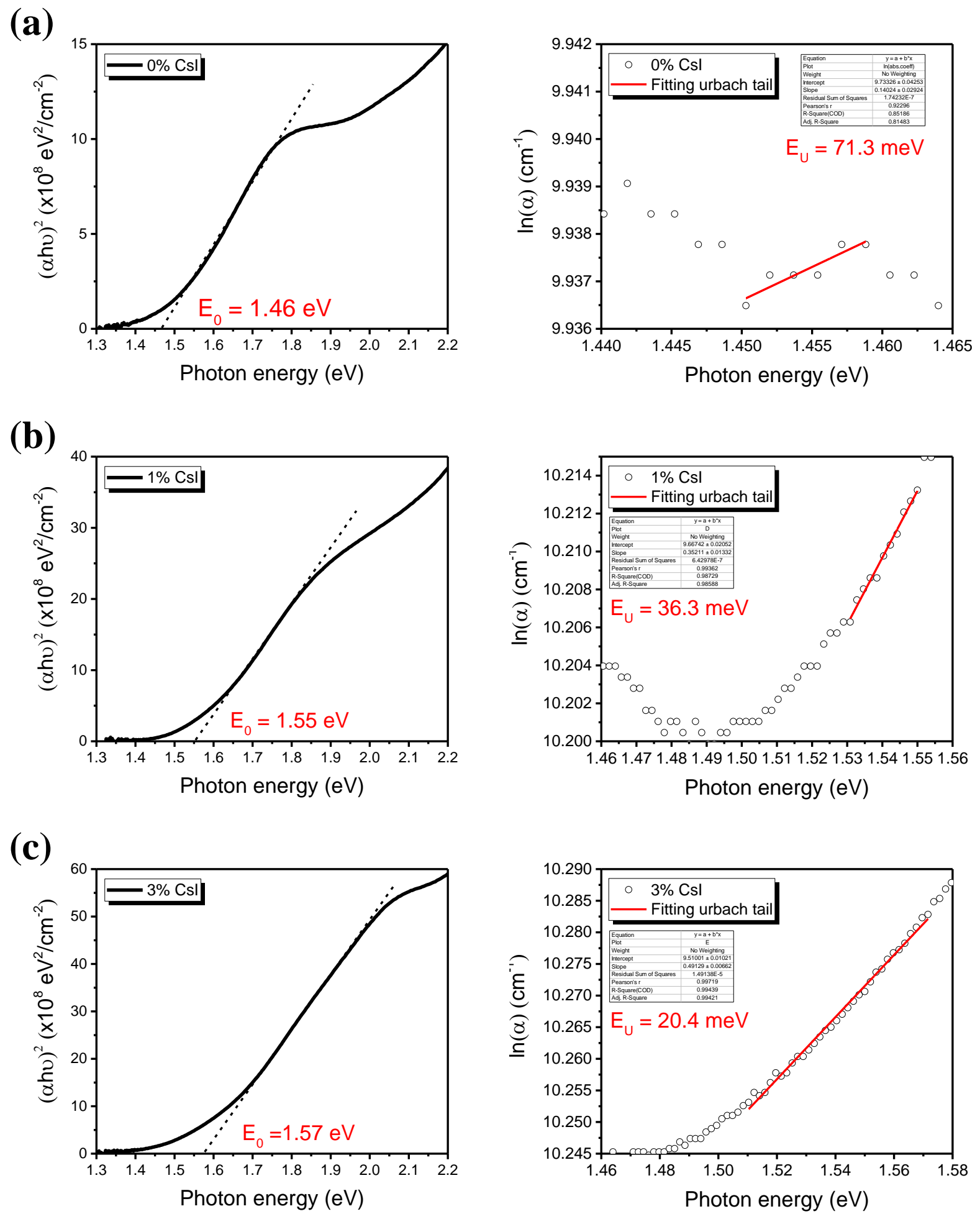

Figure S4. Tauc plot, optical gap ( $\left.\mathrm{E}_{0}\right)$ and Urbach energy ( $\mathrm{E}_{\mathrm{U}}$ ) of (a) $0 \% \mathrm{CsI}$, (b) $1 \%$ CsI and (c) $3 \%$ CsI films. 
(d)
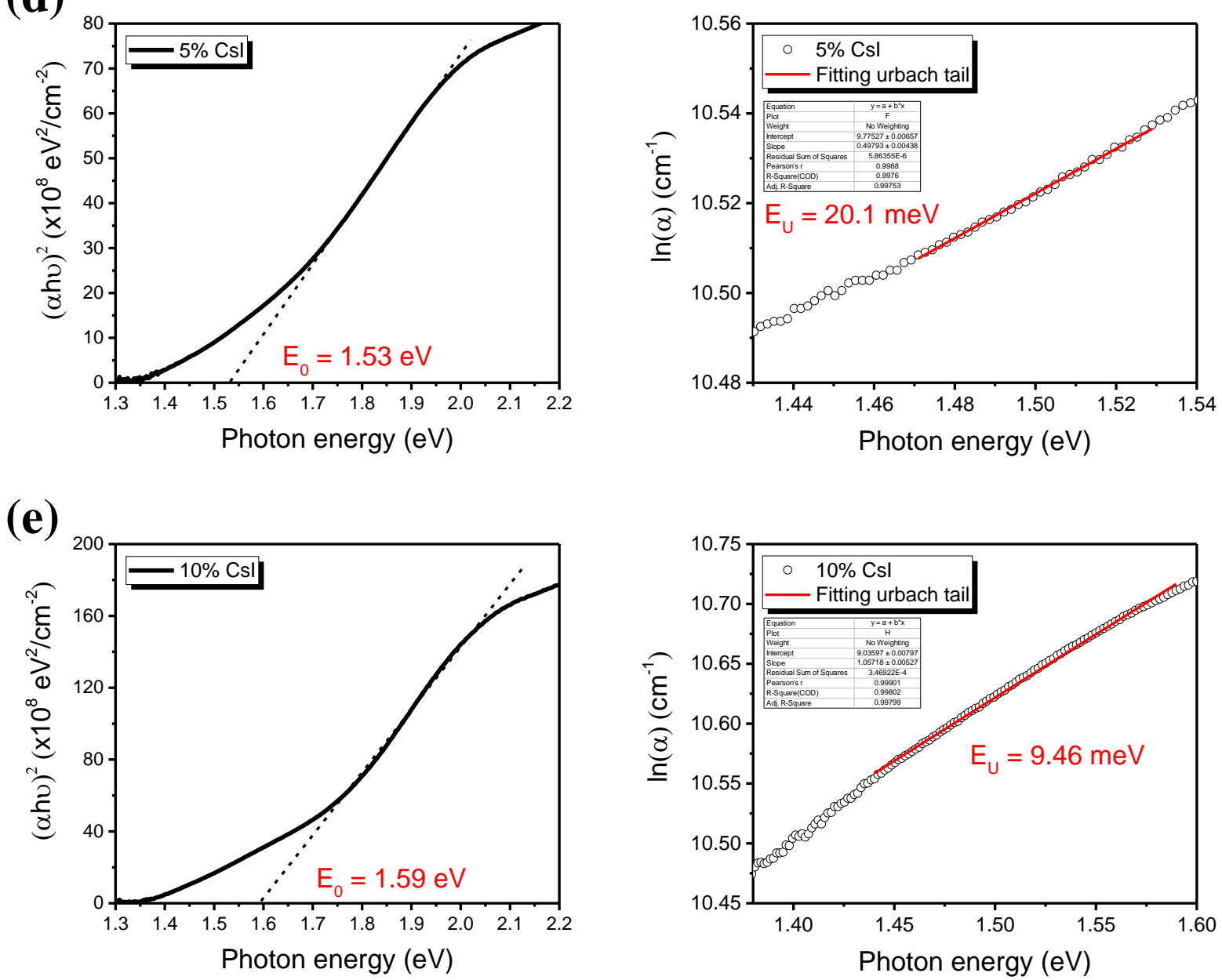

(f)
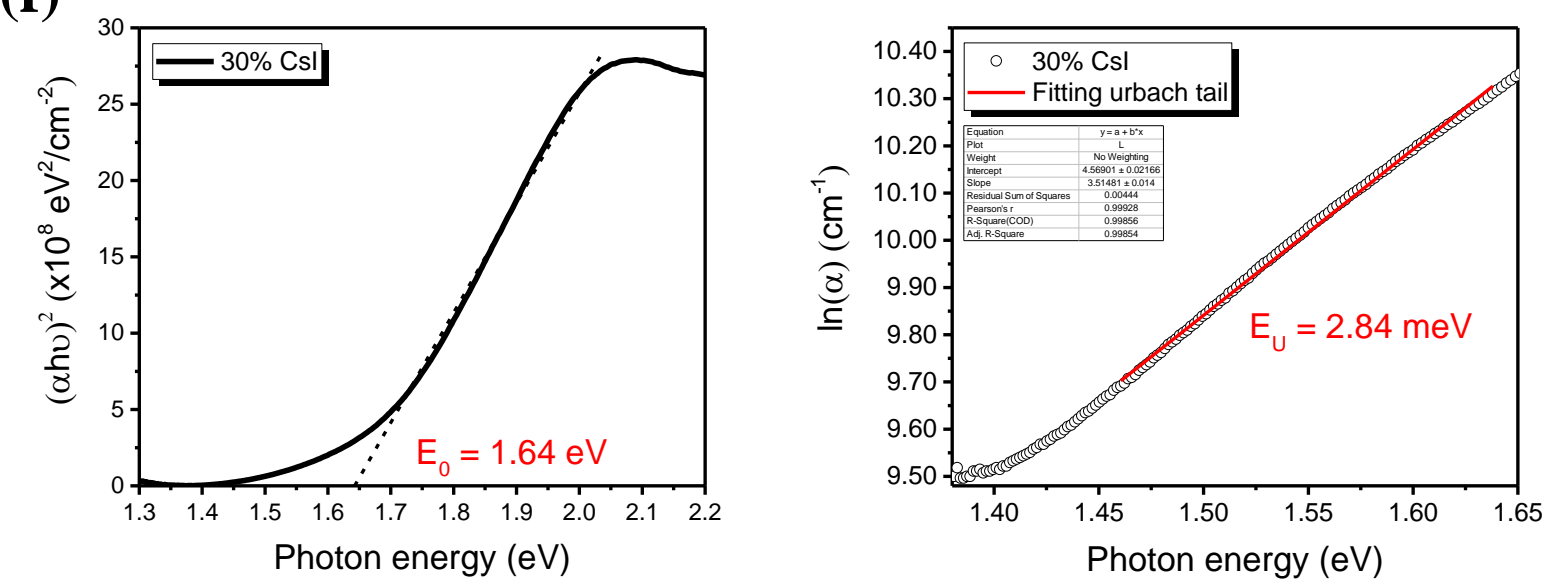

Figure S4. Tauc plot, optical gap ( $\left.\mathrm{E}_{0}\right)$ and Urbach energy $\left(\mathrm{E}_{\mathrm{U}}\right)$ of (d) $5 \%$ CsI, (e) $10 \% \mathrm{CsI}$ and (c) $30 \%$ CsI films. 

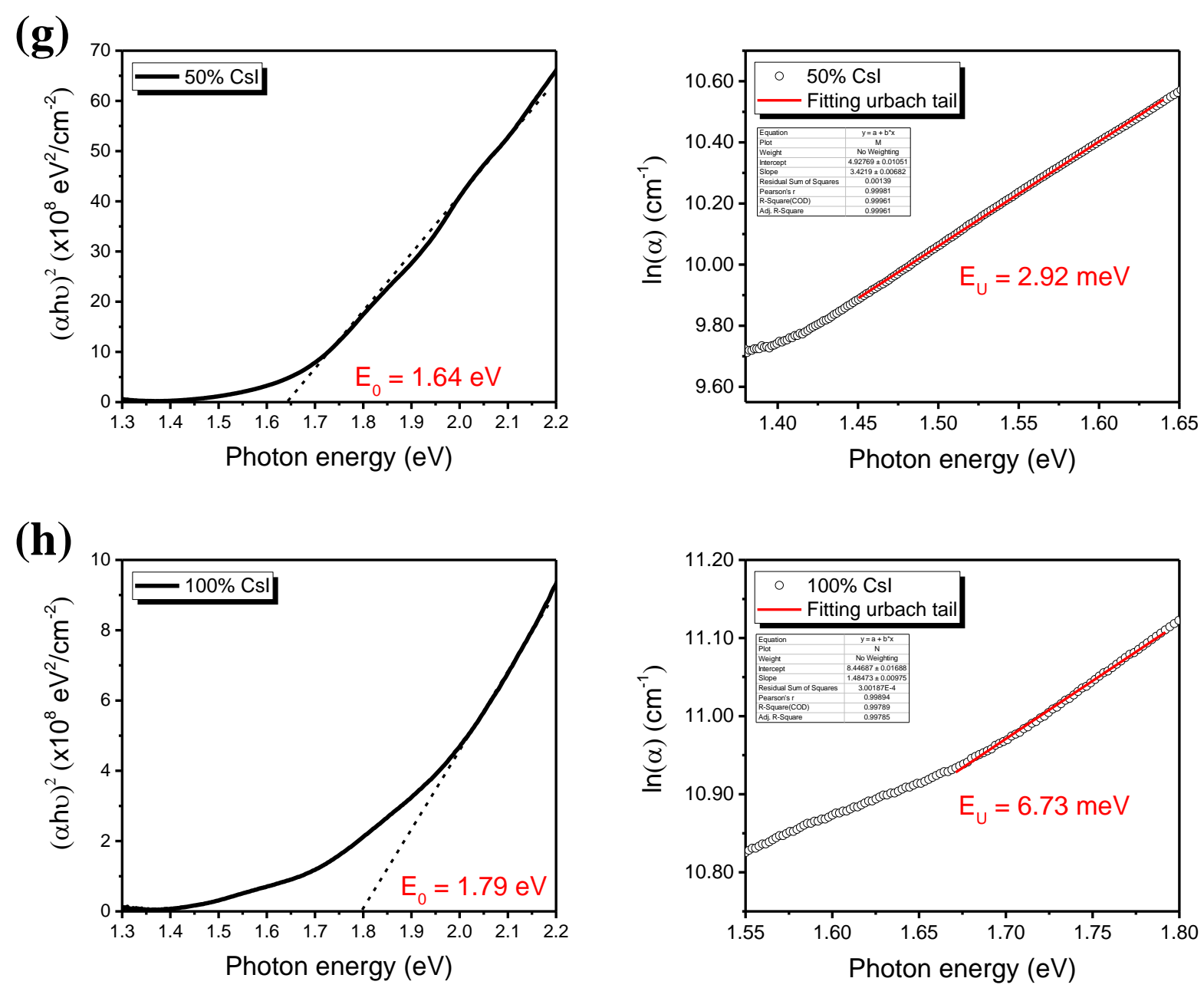

(i)

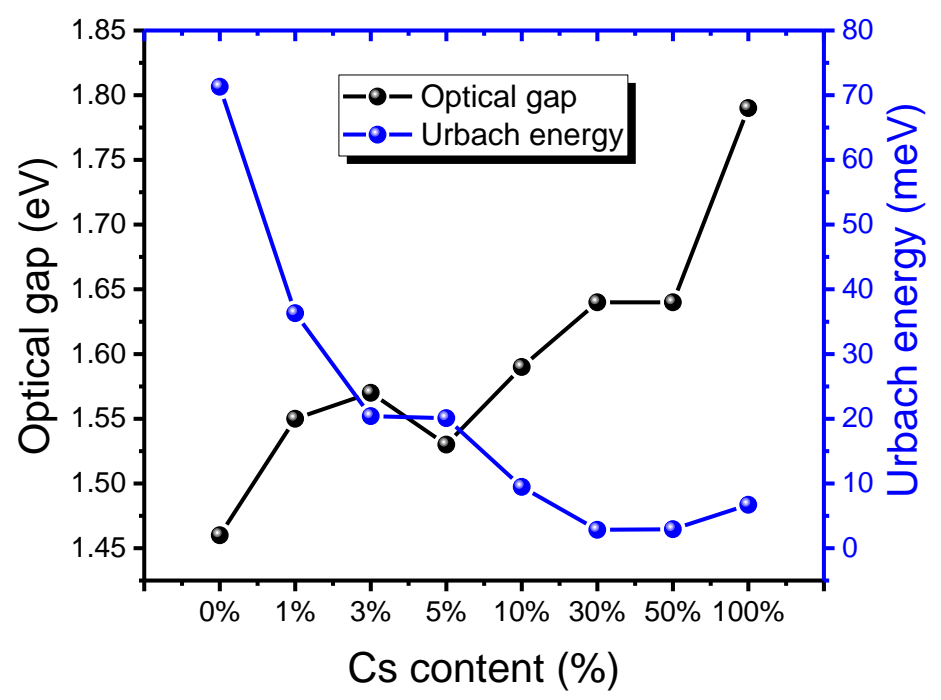

Figure S4. Tauc plot, optical gap ( $\left.\mathrm{E}_{0}\right)$ and Urbach energy (EU) of (g) 50\% CsI, (h) $100 \%$ CsI and (i) optical gap and Urbach energy versus various Cs contents (\%). 
(a)
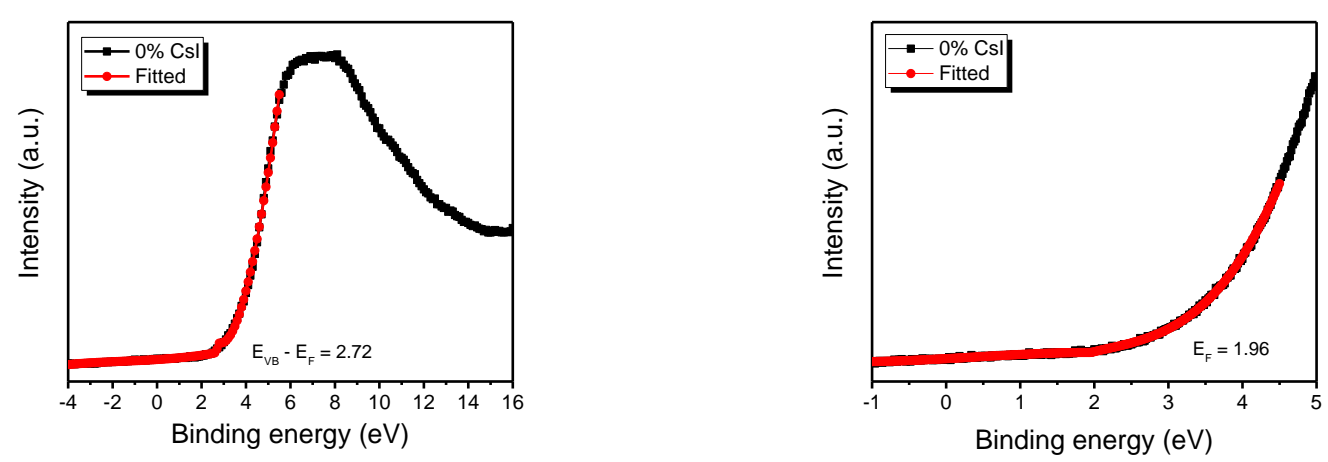

(b)
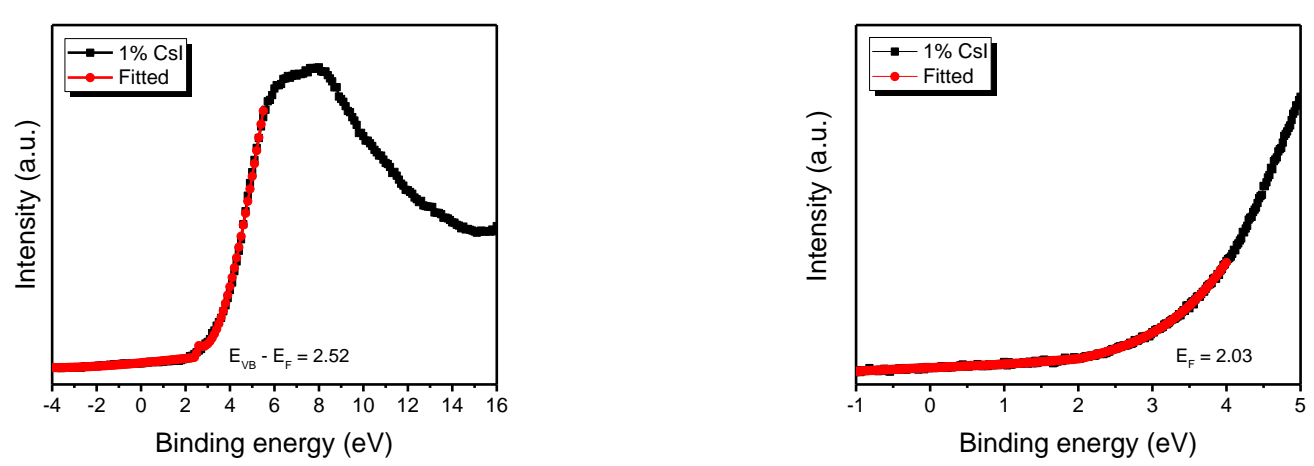

(c)
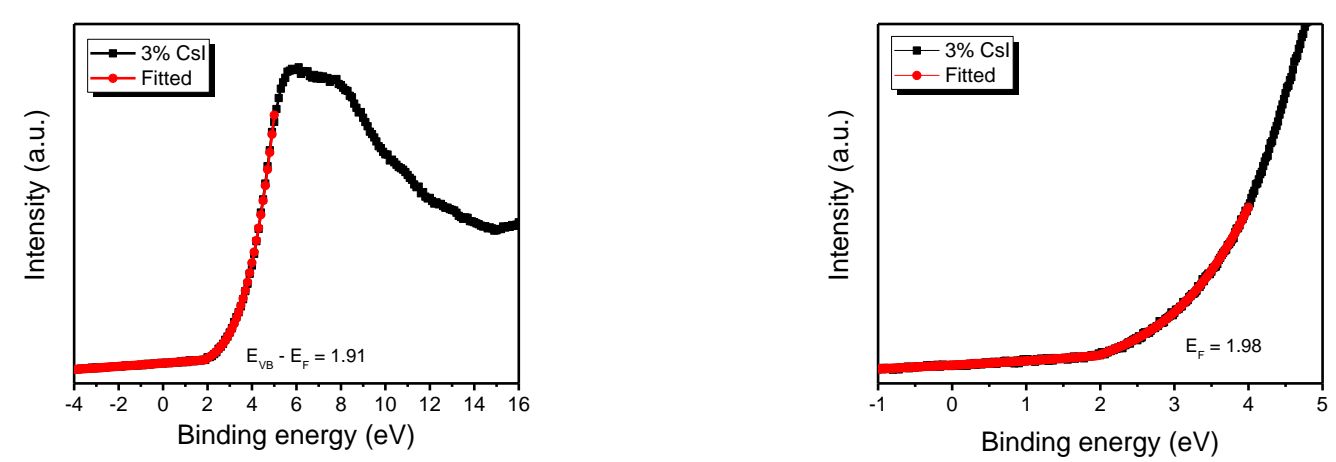

(d)
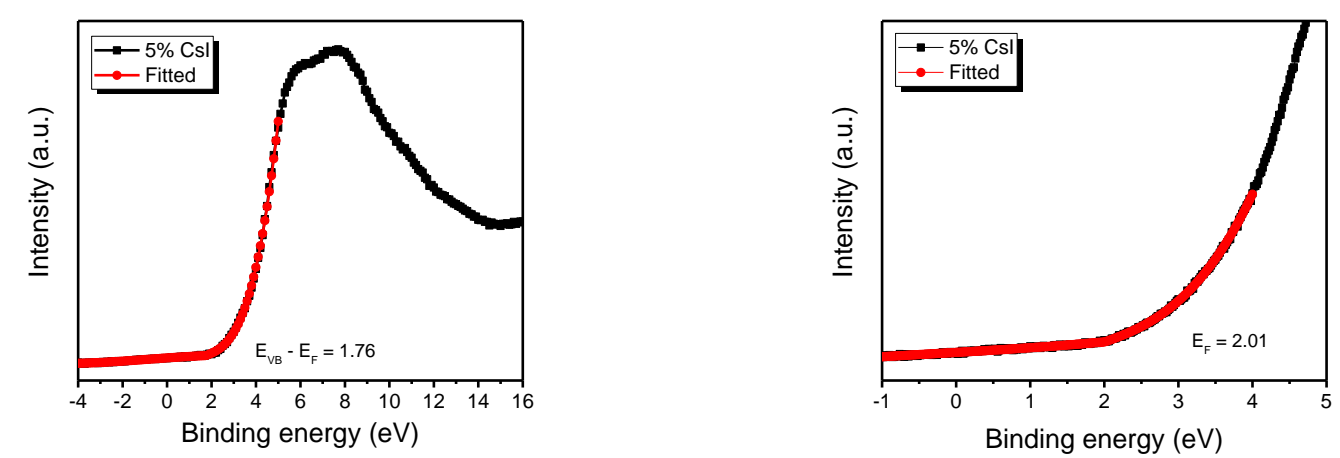

Figure S5. Fitted valence band $\left(\mathrm{EvB}_{\mathrm{B}}-\mathrm{EF}_{\mathrm{F}}\right)$ and fermi level $\left(\mathrm{E}_{\mathrm{F}}\right)$ measurements of (a) $0 \%$ CsI, (b) $1 \%$ CsI, (c) 3\% CsI and (d) $5 \%$ CsI films. 
(e)
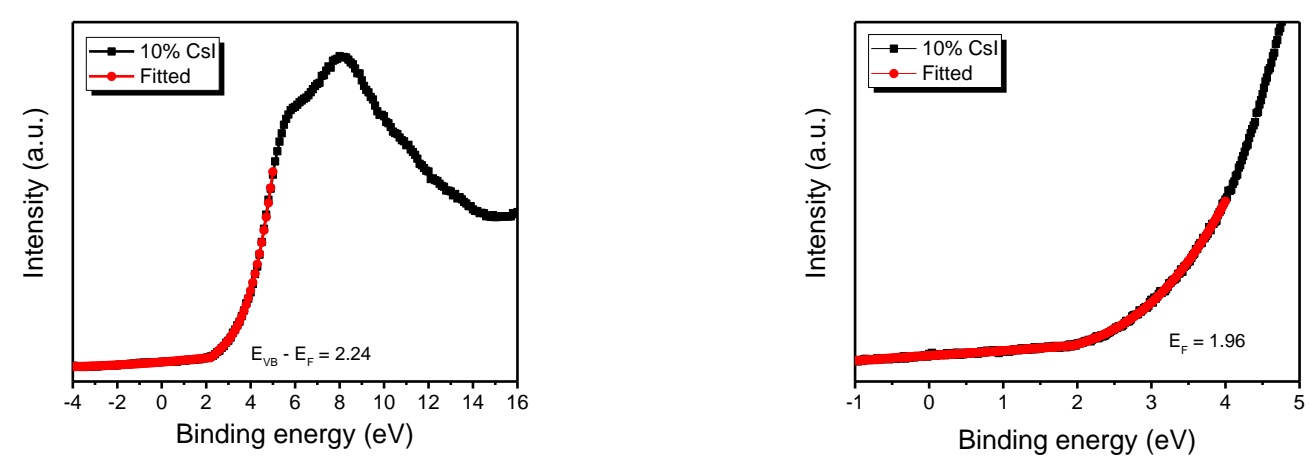

(f)
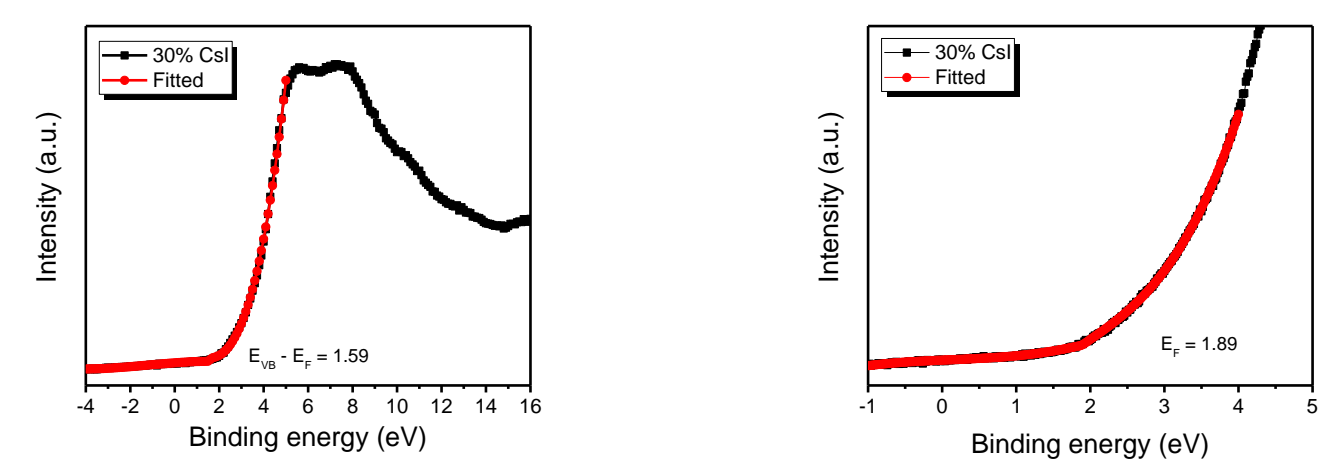

(g)
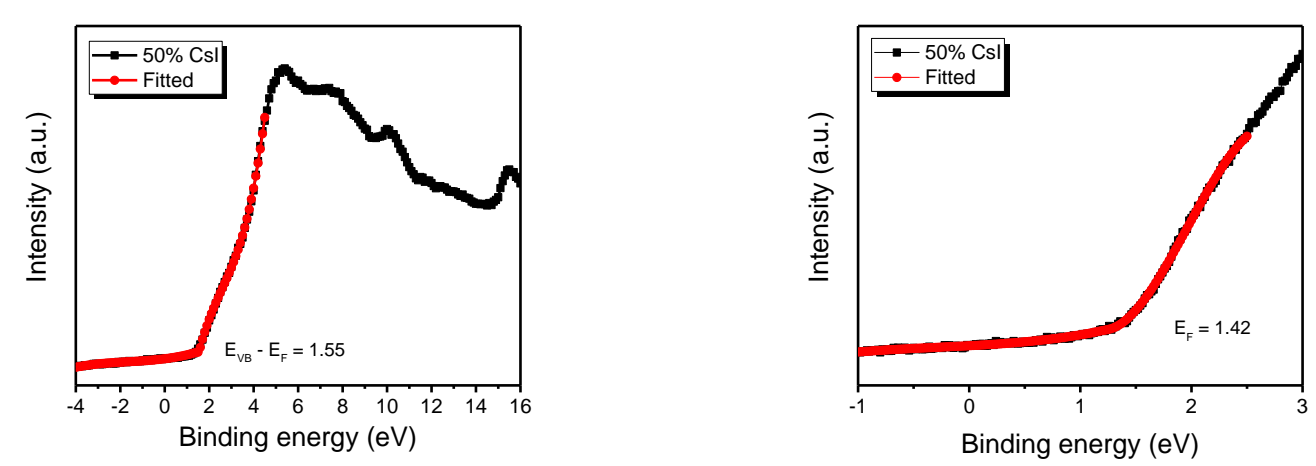

(h)
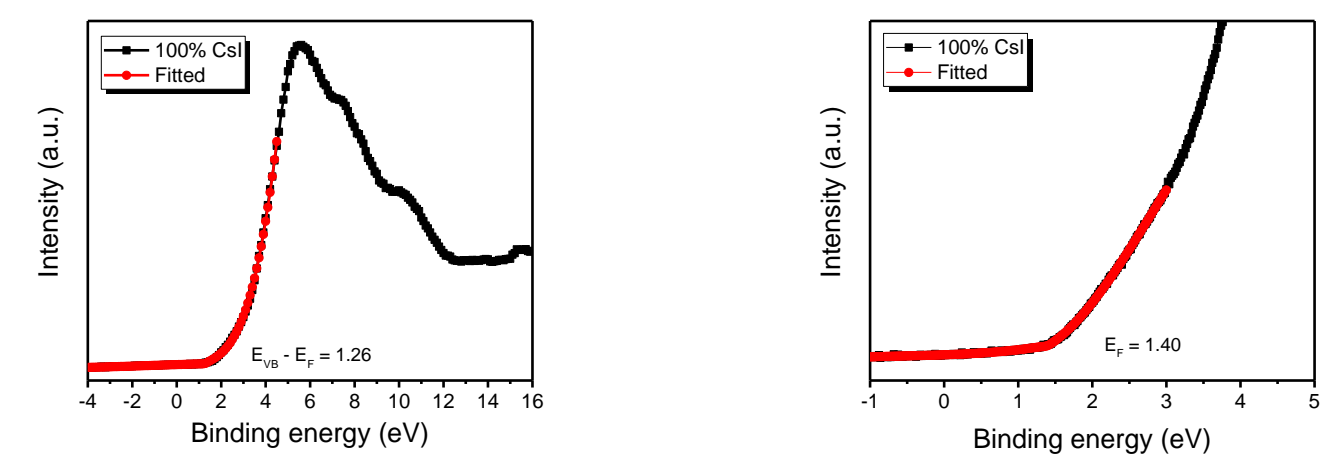

Figure S5. Fitted valence band $\left(E_{V B}-E_{F}\right)$ and fermi level $\left(E_{F}\right)$ measurements of (e) $10 \% \mathrm{CsI}$, (f) $30 \% \mathrm{CsI}$, (g) $50 \% \mathrm{CsI}$ and (h) $100 \%$ CsI films. 
Table S2. The thickness summary of 0 - 50\% CsI and 100\% CsI films by ImageJ software.

\begin{tabular}{|r|r|r|r|r|}
\hline \multicolumn{1}{|c|}{ Cs contents } & \multicolumn{2}{|c|}{$\begin{array}{c}\text { Average } \\
\text { thickness (nm) }\end{array}$} \\
\hline $\mathbf{0 \%}$ CsI & 1.850 & 1.600 & 1.733 & 1,728 \\
\hline $\mathbf{1 \%}$ CsI & 1.362 & 1.614 & 1.415 & 1,464 \\
\hline $\mathbf{3 \%}$ CsI & 1.587 & 1.548 & 1.548 & 1,561 \\
\hline $\mathbf{5 \%}$ CsI & 1.050 & 1.166 & 1.122 & 1,113 \\
\hline $\mathbf{1 0 \%}$ CsI & 1.546 & 1.608 & 1.584 & 1,579 \\
\hline $\mathbf{3 0 \%} \mathbf{C s I}$ & 1.183 & 1.100 & 1.167 & 1,150 \\
\hline $\mathbf{5 0 \%} \mathbf{C s I}$ & 1.330 & 1.330 & 1.134 & 1,265 \\
\hline $\mathbf{1 0 0 \%} \mathbf{C s I}$ & 1.540 & 1.504 & 1.504 & 1,516 \\
\hline
\end{tabular}
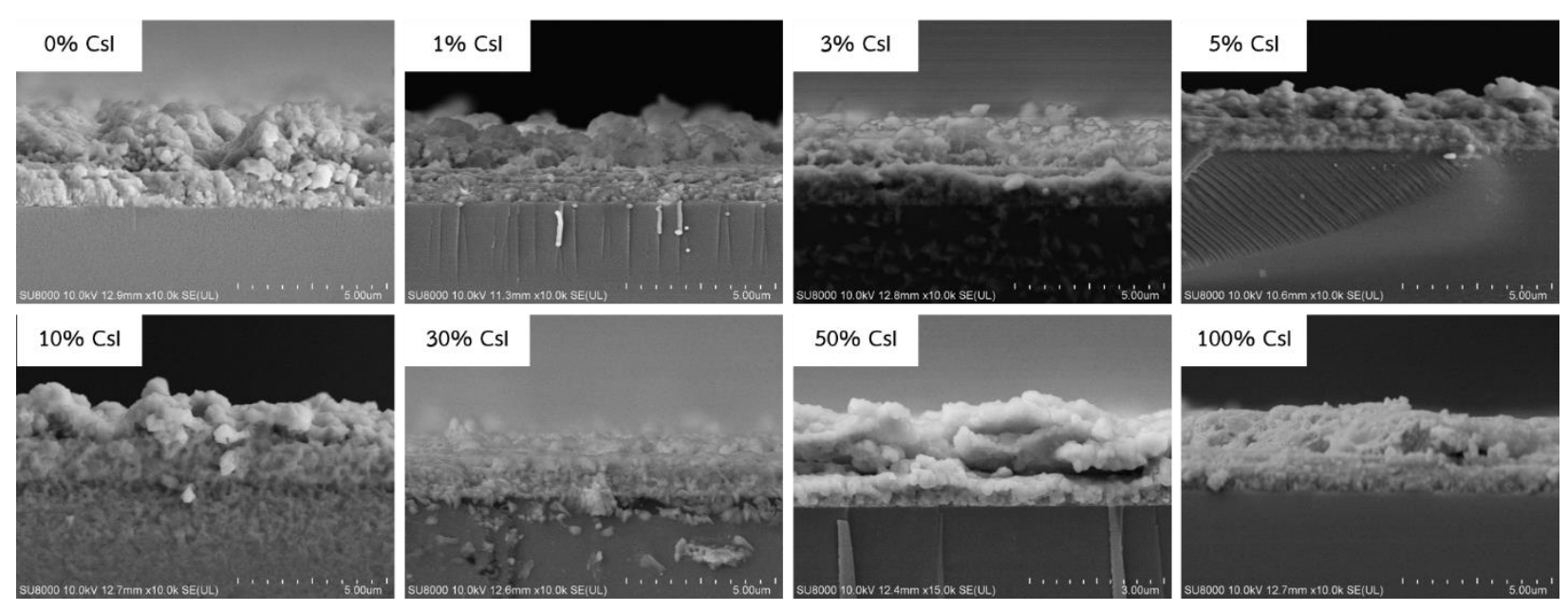

Figure S6. SEM cross-sections of 0 - 50\% and 100\% CsI films. 
(a)

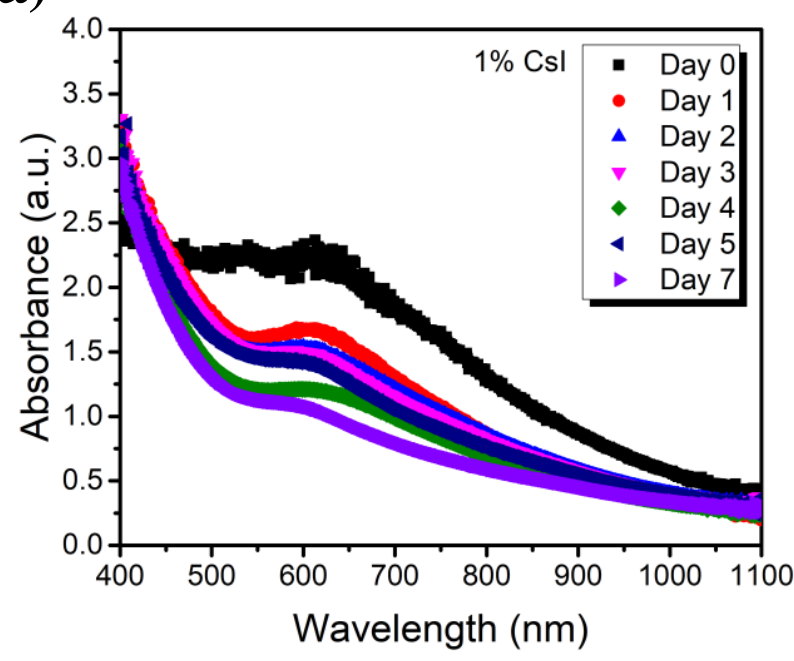

(c)

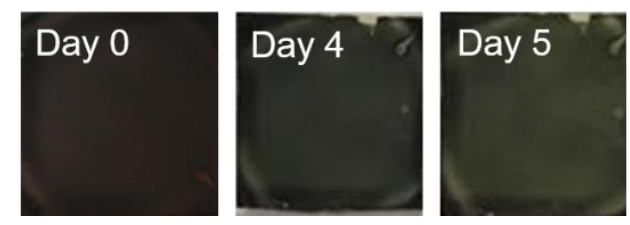

(b)

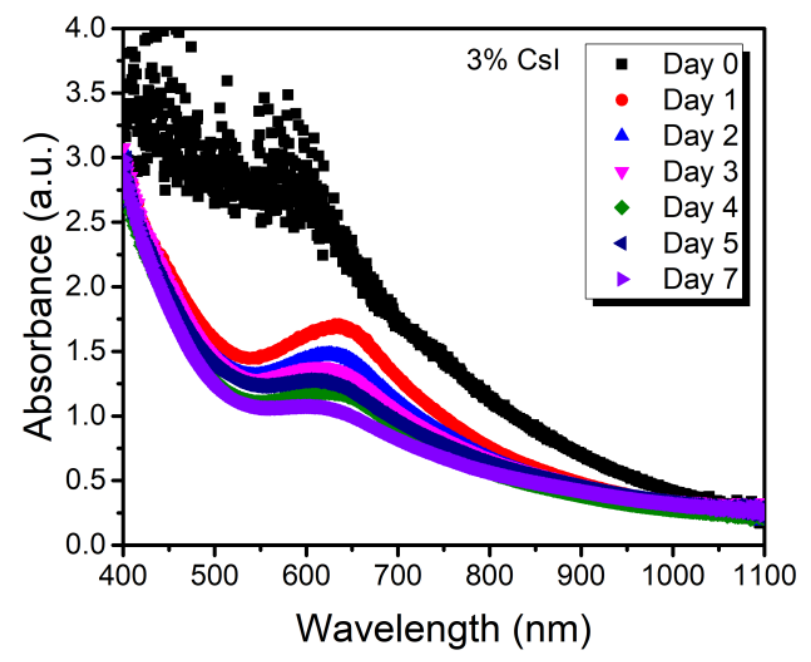

(d)

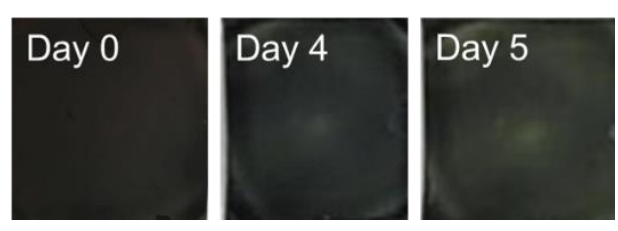

Figure S7. Film stability over 7 days of (a) $1 \%$ CsI and (b) $3 \%$ CsI. Film appearances of fresh film (Day 0), Day 4 and Day 5 of (c) 1\% CsI and (d) 3\% CsI films. 


\section{References}

(1) Boonthum, C.; Pinsuwan, K.; Ponchai, J.; Srikhirin, T.; Kanjanaboos, P. Reconditioning Perovskite Films in Vapor Environments through Repeated Cation Doping. Appl. Phys. Express 2018, 11 (6).

(2) Li, X.; Bi, D.; Yi, C.; Décoppet, J. D.; Luo, J.; Zakeeruddin, S. M.; Hagfeldt, A.; Grätzel, M. A Vacuum Flash-Assisted Solution Process for High-Efficiency Large-Area Perovskite Solar Cells. Science 2016, 353 (6294), 58-62.

(3) Ozaki, M.; Katsuki, Y.; Liu, J.; Handa, T.; Nishikubo, R.; Yakumaru, S.; Hashikawa, Y.; Murata, Y.; Saito, T.; Shimakawa, Y.; et al. Solvent-Coordinated Tin Halide Complexes as Purified Precursors for Tin-Based Perovskites. ACS Omega 2017, 2 (10), 7016-7021.

(4) Shard, A. G. Practical Guides for X-Ray Photoelectron Spectroscopy: Quantitative XPS. J. Vac. Sci. Technol. A 2020, 38 (4), 041201.

(5) Nakajima H. hidecode221b/xps-excel-macro: fix update element in graph sheet. https://doi.org/10.5281/zenodo.1320738 (accessed July 11, 2021). 